\title{
Aliskiren Hemifumarate
}

National Cancer Institute

\section{Source}

National Cancer Institute. Aliskiren Hemifumarate. NCI Thesaurus. Code C65223.

An orally active nonpeptide renin inhibitor with antihypertensive activity. Aliskiren selectively binds to the S3 sub-pocket of renin, an enzyme in the renin-angiotensinaldosterone system (RAAS) that is responsible for converting angiotensinogen to angiotensin I (AT I). By inhibiting the activity of renin, the conversion to AT I is prevented, which in turn prevents the conversion of AT I to AT II. This prevents arterial vasoconstriction by AT II and inhibits the production of aldosterone by AT II. As aldosterone causes re-uptake of sodium and water and eventually an increase in extracellular volume, aliskiren is able to prevent the effects that contribute to an increase in blood pressure. 